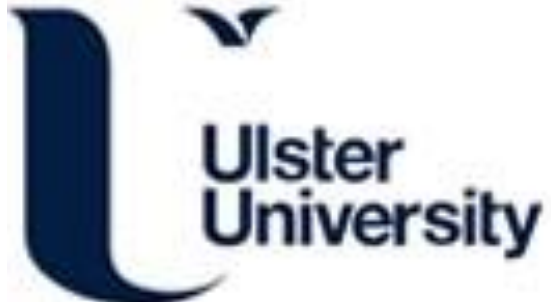

\section{Use of microwave conditioning to rapidly age asphalt mixes}

Mitchell, R., Woodward, D., \& Ryan, D. (2013). Use of microwave conditioning to rapidly age asphalt mixes. In Unknown Host Publication (pp. 1211-1218). American Society of Civil Engineers.

Link to publication record in Ulster University Research Portal

\section{Published in:}

Unknown Host Publication

Publication Status:

Published (in print/issue): 01/01/2013

\section{Document Version}

Publisher's PDF, also known as Version of record

\section{General rights}

Copyright for the publications made accessible via Ulster University's Research Portal is retained by the author(s) and / or other copyright owners and it is a condition of accessing these publications that users recognise and abide by the legal requirements associated with these rights.

\section{Take down policy}

The Research Portal is Ulster University's institutional repository that provides access to Ulster's research outputs. Every effort has been made to ensure that content in the Research Portal does not infringe any person's rights, or applicable UK laws. If you discover content in the Research Portal that you believe breaches copyright or violates any law, please contact pure-support@ulster.ac.uk. 


\title{
Use of microwave conditioning to rapidly age asphalt mixes
}

\author{
Ruth Mitchell ${ }^{1}$, David Woodward ${ }^{2}$ and Donal Ryan ${ }^{3}$ \\ ${ }^{1}$ University of Ulster, School of the Built Environment, Newtownabbey, Co. Antrim, \\ Northern Ireland; email mitchell-r4@email.ulster.ac.uk \\ ${ }^{2}$ University of Ulster, School of the Built Environment, Newtownabbey, Co. Antrim, \\ Northern Ireland; email wdh.woodward@ulster.ac.uk \\ ${ }^{3}$ University of Ulster, School of the Built Environment, Newtownabbey, Co. Antrim, \\ Northern Ireland; email d.ryan@ulster.ac.uk
}

\begin{abstract}
Literature shows that microwave conditioning has been used to age bitumen. There has been less research using microwaves to accelerate the aging of asphalt mixtures. This paper considers the use of microwave heating as a means of rapidly aging gyratory prepared test specimens. Indirect Tensile Stiffness Modulus, assessed using the Nottingham Asphalt Tester was used to assess its affect. It was found that microwave conditioning had a significant effect on retained stiffness. Although the asphalt mixture test specimens went through a cycle of recovery after initial microwave heating, there was a longer term reduction in retained stiffness. This suggests that microwave heating of compacted asphalt mixture test specimens may be a simple and rapid way to accelerate the aging of asphalt mixtures. The proposed test is still in its early stages of development and the study reported in this paper is still inconclusive.
\end{abstract}

\section{INTRODUCTION}

The need to predict asphalt durability is becoming increasingly important. In the UK there is no specific method available to assess asphalt mix durability. Comparing stiffness data before and after soaking in water is commonly used. However, this relates more to the aggregate / bitumen bond rather than the effect of bitumen aging in-service. Airey (2003) reviewed different methods used to age bituminous pavements to determine their long term performance. This found that most methods consider just the bitumen component, rather than the actual mix. There were very few methods that used micro-waves.

Al-Ohaly et. al. (1988) reported how microwave energy heats asphalt. Some materials heat much better than others with aggregates heating well with bitumen not as well. Aggregates heat well because of factors such as absorbed moisture. Typically, the aggregate heats first and then contributes to heating its bitumen 
coatings. Shoenberger et. al. (1995) used microwave radiation to heat Reclaimed Asphalt Pavement (RAP) assuming that this would cause less damage than directly applied heat. Clark (1996) noted that when microwave energy to heat samples the microwaves penetrate through the material instead of focusing the heat on the surface leading to a quicker and more uniform heating process.

Bishara et. al. (1995) found that asphalts commonly have relatively low dielectric losses and dissipation factors. These factors determine how quickly materials heat when exposed to microwave radiation. Lower numbers mean longer heating times. Exposing bitumen to microwave radiation causes the molecules to rotate and break the bonds between the molecules. Once microwaving is stopped these bonds reform in different ways meaning that the material has changed on a fundamental level. Bishara et. al. (1995) developed a test similar to the Rolling Thin Film Oven Testing (RTFOT) with Pressure Ageing Vessel (PAV) in a much shorter time of 3 hours. Further studies (Bishara et. al. 1996, 1999 and 2003) improved the test procedure. This paper gives initial findings for a study to determine whether it is possible to use microwave heating to rapidly age asphalt materials.

\section{DEVELOPMENT OF A TEST PROCEDURE}

A domestic microwave oven was used in this investigation. It had a input power of 1100-1150W and an output power of 650-700W. Asphalt mixture test specimens $150 \mathrm{~mm}$ in diameter were prepared using gyratory compaction. Two types of asphalt mix were used i.e. a 14mm SMA with polymer modified bitumen (SMA) and a cold mix $3 \mathrm{~mm}$ temporary repair mix (Repair mix). These were chosen as they had differing aggregate grades, bitumen and engineering properties.

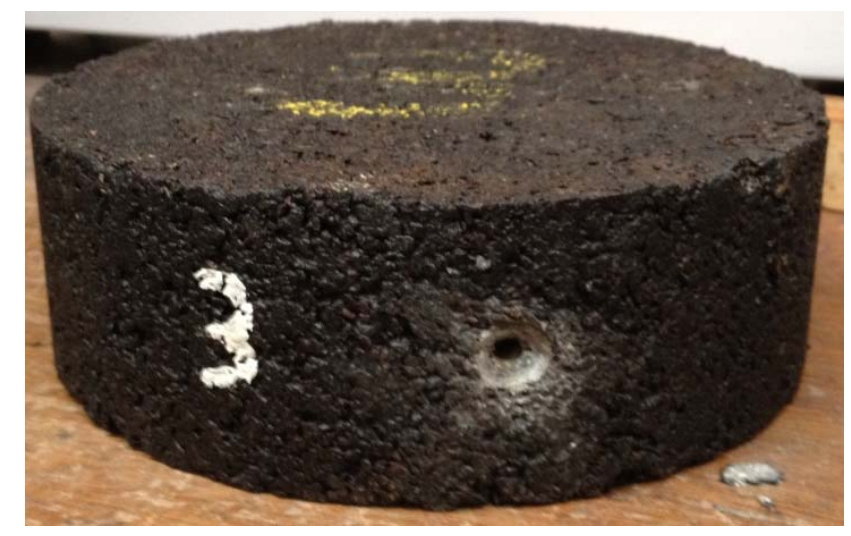

Figure 1. Test specimen with hole drilled to determine temperature internal temperature 
The investigation first determined how these two types of asphalt were affected by microwave heating. A hole was drilled into the centre of both asphalt mixture test specimens as shown in Figure 1. The asphalt mixture test specimen was placed in the microwave oven and subjected to 1 minute of heating a full power. A thermocouple probe was immediately inserted into the hole to measure temperature at the centre of the asphalt mixture test specimen. Surface temperature was measured using a surface pipe thermocouple probe at 6 locations. The asphalt mixture test specimen was quickly placed back into the microwave and the procedure repeated.

The investigation then assessed whether repeated periods of heating in a microwave oven had an effect on asphalt mix stiffness. The Indirect Tensile Stiffness Modulus (ITSM) method using a Nottingham Asphalt Tester was chosen (BS EN 12697-26, 2004). This test method is quick to do, non-destructive and widely used in the UK and Europe as a specification requirement. The standard temperature for the ITSM test is $20^{\circ} \mathrm{C}$. Small variation in test temperature can have a significant effect on the results obtained.

Preliminary testing of a $14 \mathrm{~mm}$ SMA mixture test specimen found 3 minutes heating in the microwave oven resulted in the test specimen being too hot to test for ITSM. So, a procedure was investigated that first assessed the test specimen for initial ITSM stiffness, then subjected it to 1 minute of microwave heating, determining its ITSM stiffness immediately and then again after 40 minutes. This was repeated 5 times over a 5 hour period. Further ITSM testing was carried out after 24 and 48 hours.

The investigation then considered microwaving asphalt mixture test specimens for 5 minutes and then allowing 24 hours before ITSM stiffness testing. It was found that the 5 minute period of microwave heating was too severe. These caused the compacted asphalt mixture test specimens to loose cohesiveness, deform and so could not be assessed for ITSM stiffness. The duration of microwave heating was reduced to 3 minutes to address the issue of deformation.

The method was further modified to fit into a working week and to assess the impact of soaking in water. The test method started Monday morning with assessment of initial ITSM stiffness followed by 3 minutes of microwaving. 24 hours later the test specimen was assessed for ITSM stiffness and then subjected to a further 3 minutes of microwaving. This was repeated 4 times over the week with the test specimen allowed to recover in an environmental chamber at $20^{\circ} \mathrm{C}$ for 48 hours over the weekend. A final ITSM stiffness was determined on Monday morning. To assess the impact water the test specimens were soaked for 4 hours prior to 3 minutes microwaving. 


\section{RESULTS AND DISCUSSION}

The following section discusses the results obtained during this initial development of a test procedure. Figure 2 plots the increase in measured temperature for the two types of asphalt. The plots show that despite the difference in asphalt mixture, the temperature measured in the centre of the compacted test specimen was similar for both mixtures. There was some variation of surface temperature with the SMA being greater.

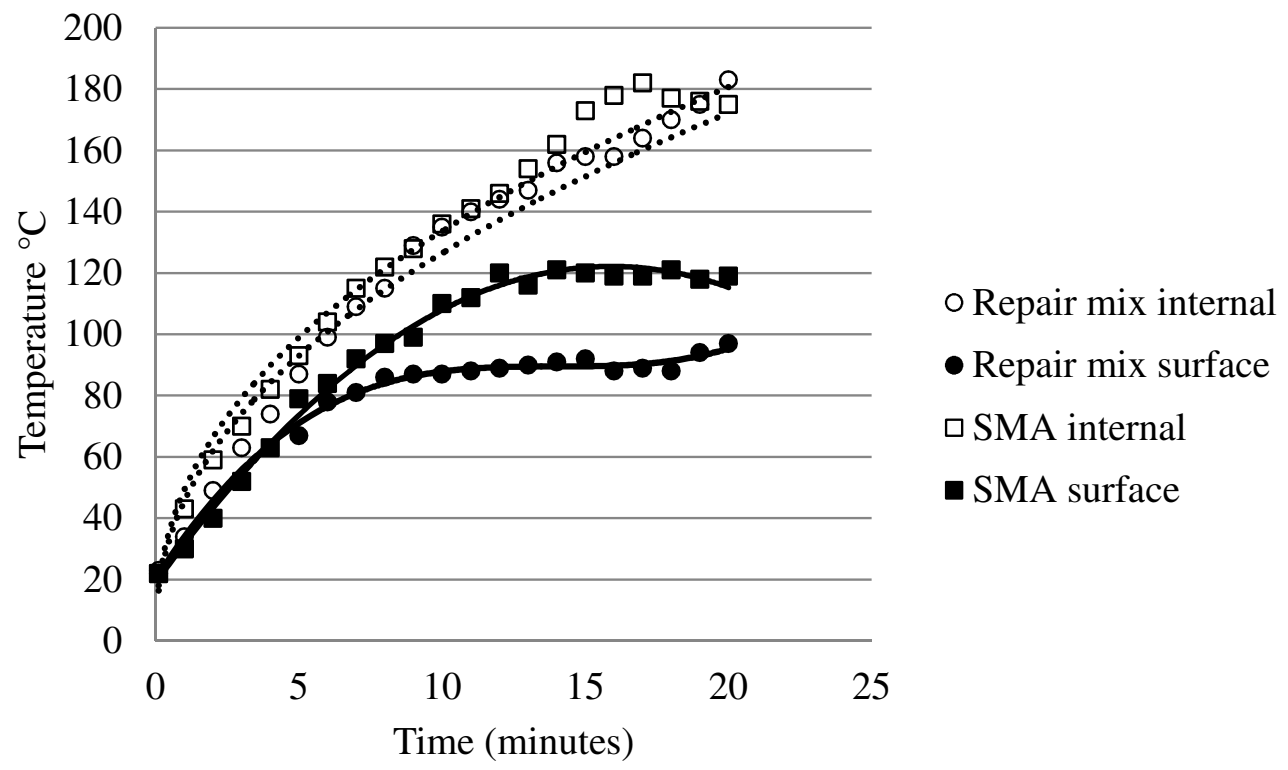

Figure 2. Measured temperatures

Figure 3 plots data for a SMA test specimen for 4 cycles of 1 minute microwave heating followed by allowing to cool in an environmental chamber at $20^{\circ} \mathrm{C}$. The data is expressed as Retained Stiffness of the original ITSM value prior to the start of microwave heating. This shows how ITSM stiffness of the test specimen varies in response to heating and how it recovers stiffness with time. There was significant variation in ITSM stiffness during testing. The data shows how heating and recovery ITSM data varies in 1 cycle. This shows ITSM to recover during the 40 minutes spent in the environmental chamber. The recovery of ITSM over the 24 hour and 48 hour period was greater.

There was a small but significant overall reduction in ITSM at the end of the 4 cycle test period. The SMA assessed was a premium quality product and any reduction in mix stiffness was expected to be small. As this investigation deals with development of a potential test method a sensitivity / statistical analysis has still to be done. For the purpose of this paper the authors were more interested in determining whether this method offered a viable solution. 
ITSM retest after 48 hours

ITSM retest after 24 hours

5 th ITSM retest

5th minute heat

4th ITSM retest

4th minute heat

3rd ITSM retest

3rd minute heat

2nd ITSM retest

2nd minute heat

1st ITSM retest

1 st minute heat

Start of cycle ITSM

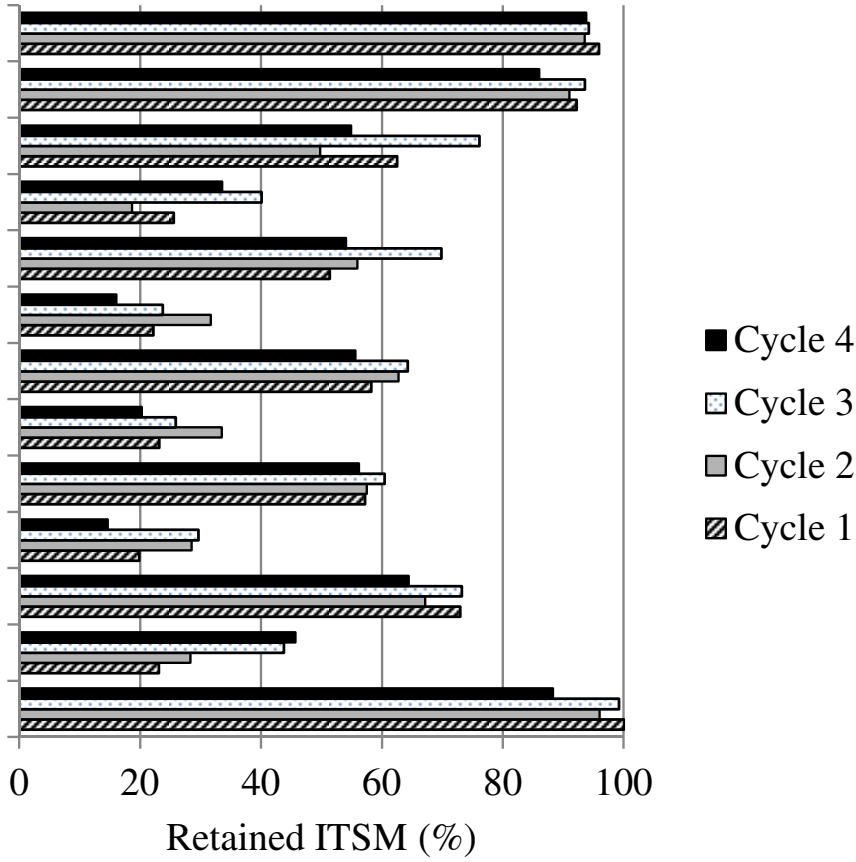

Figure 3. Change in retained ITSM over 4 test cycles

ITSM retest after 48 hours

ITSM retest after 24 hours

5 th ITSM retest

5 th minute heat

4th ITSM retest

4th minute heat

3rd ITSM retest

3rd minute heat

2nd ITSM retest

2nd minute heat

1 st ITSM retest

1 st minute heat

Start of cycle ITSM

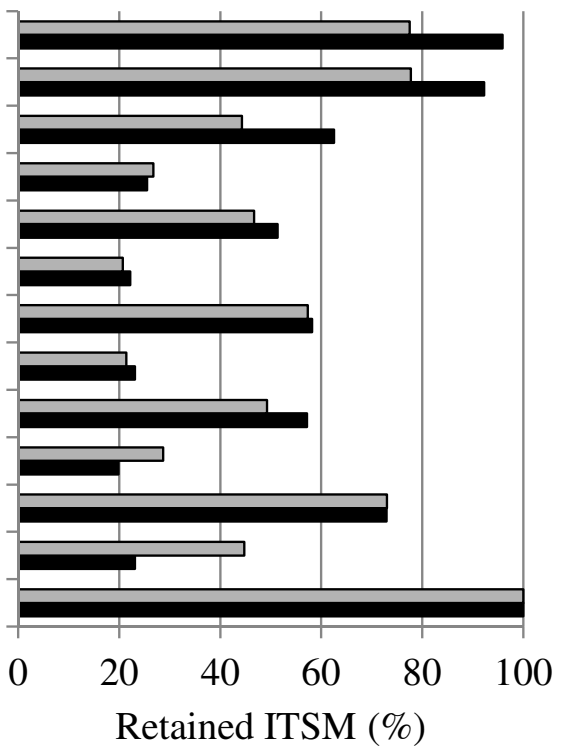

$\square$ Repair mix

SMA

Figure 4. Comparison of SMA and repair mix over 1 cycle 


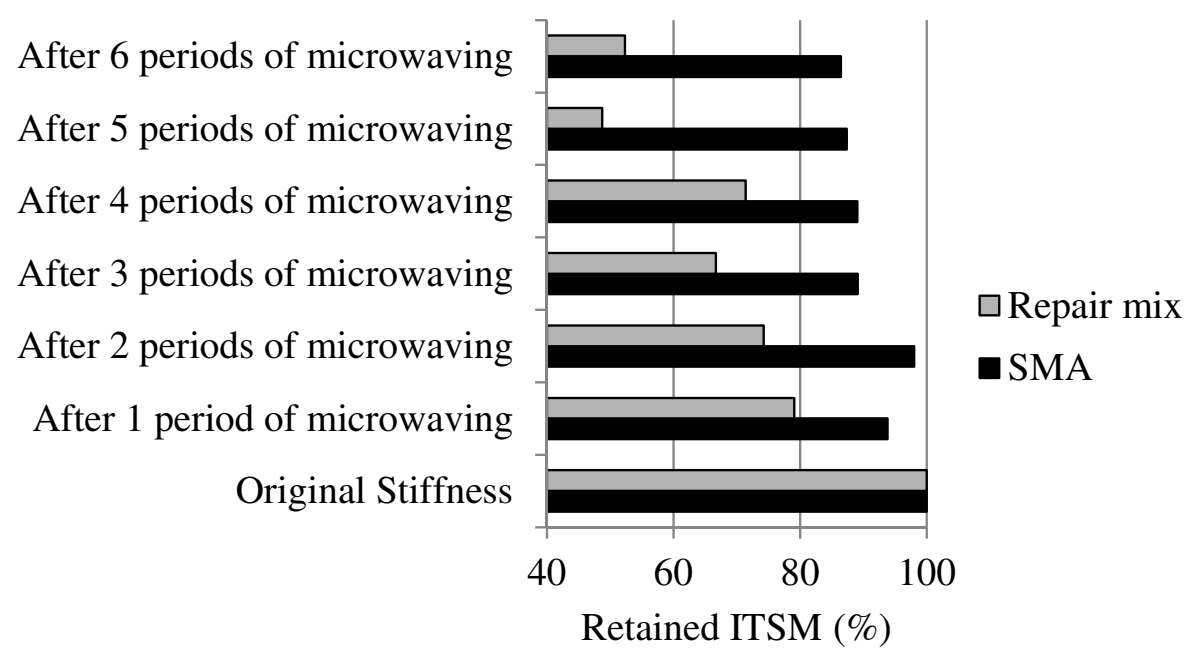

Figure 5. Comparison of SMA and repair mix over 6 periods of microwaving

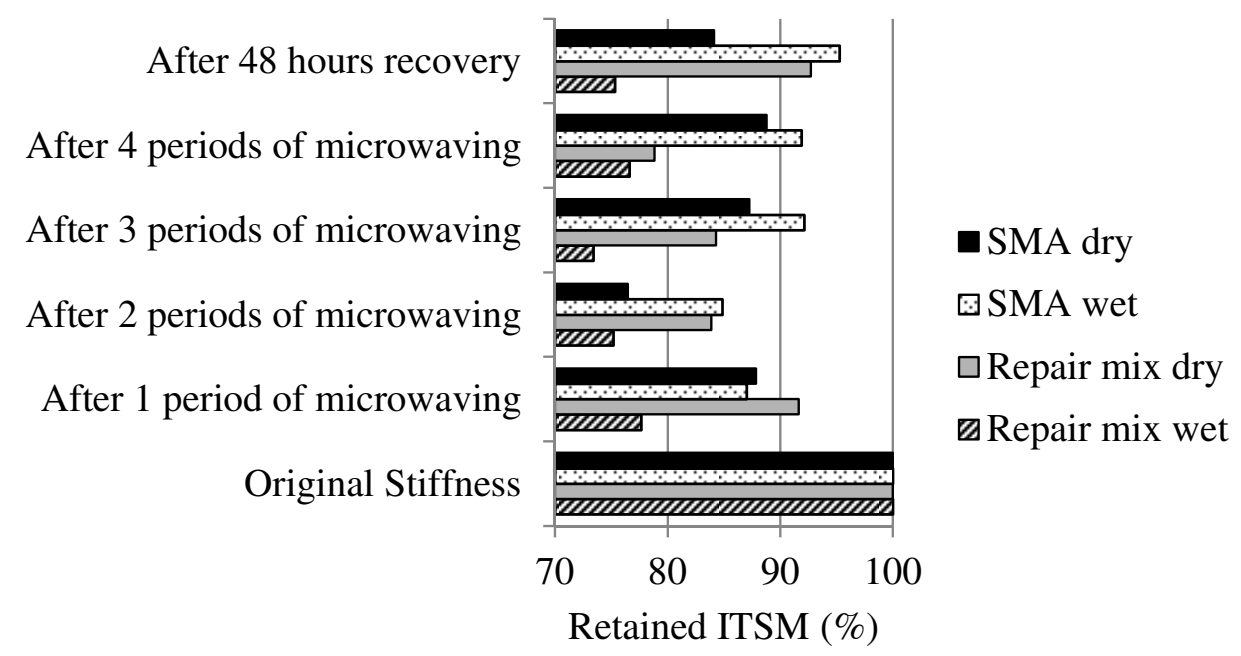

Figure 6. Comparison of dry and soaked conditions

Figure 4 compares data for SMA and Repair mix test specimens during their first cycle. Both types of asphalt follow similar trends in response to heating and recovery. However, the effect of microwave heating is more pronounced for the Repair mix asphalt. This was expected and probably reflects the different types of bitumen used to make these differing asphalt mixes. Figure 5 compares retained ITSM for SMA and Repair mix. This shows the Repair mix to have a Retained ITSM of $52 \%$ compared to $86 \%$ for the SMA. Figure 6 compares the change in Retained ITSM stiffness for dry and soaked test specimens. The results show the two asphalt materials to behave differently when soaked in water at $20^{\circ} \mathrm{C}$ compared to their dry 
test data. The dry SMA Retained ITSM values are lower than the soaked values. The dry repair mix values are higher than the soaked values.

The initial investigations reported in this paper suggest that microwave heating could be a potential methodology to quickly simulate some aspect of an asphalt mix related to the aging. It has been shown that microwave heating causes asphalt mixture test specimens to heat from the inside to temperatures higher than the outside of the specimen. In 5 minutes the inside of a test specimen can reach up to $100^{\circ} \mathrm{C}$. Using the non-destructive ITSM stiffness test as an indicator of the effect of microwave heating, it has been shown that repeated short periods of microwave heating can reduce its stiffness. Recovery of ITSM stiffness after microwave heating occurs in the short-term as the test specimen cools over a period of approximately 1 hour and the surface is at room temperature. Recovery continues over longer periods of 24 and 48 hours.

\section{CONCLUSIONS}

This paper has given initial findings for a study to determine whether it is possible to use microwave heating to rapidly age asphalt mixtures. The study was based on 2 materials that were quite different i.e. $14 \mathrm{~mm}$ SMA with polymer modified bitumen and a $3 \mathrm{~mm}$ cold Repair mix used for temporary pot hole repair. It was found that the internal temperature for both compacted asphalt mixture test specimens was similar during heating. Microwave heating for 5 minutes caused deformation of the compacted test specimen.

The effect of repeated microwave heating for 3 minutes followed by cooling found a reduction in ITSM stiffness. There was less reduction for the $14 \mathrm{~mm}$ SMA. ITSM stiffness was found to recover after cooling. Increased cooling duration resulted in greater ITSM stiffness recovery. Generally, soaking in water reduced ITSM stiffness. However, the presence of water within the compacted asphalt mixture test specimen needs further investigation.

This test involving microwave heating of compacted asphalt mixture test specimens is still in the early stages of development and the study is still inconclusive. The loss in ITSM caused by microwave heating or the amount of ITSM recovery could be used as indicators of asphalt mixture durability. Durability may be defined as the ability of any product to last over the course of its designed

life. Therefore recovery of an asphalt mixture when subjected to microwave heating may be an indicator of durability. 


\section{ACKNOWLEDGEMENT}

The research presented in this paper was funded by the National Roads Authority of Ireland through the NRA Research Fellowship Programme. The views expressed are not necessarily those of the National Roads Authority.

\section{REFERENCES}

Airey G.D. (2003) State of the Art Report on Ageing Test Methods for Bituminous Pavement Materials. International Journal of Pavement Engineering, 4:3, p.p. $165-176$.

Al-Ohaly A.A and Terrel R.L. (1988) Effect of Microwave Heating on Adhesion and Moisture Damage of Asphalt Mixtures. Transport Research Board Vol. 1171 p.p. 27-36.

Bishara S.W. and McReynolds R.L. (1995) Effect of Microwave Energy on the Properties of Asphalt and Its Use as an Aging Tool Transport. Transport Research Board Record 1488, pp. 1-12.

Bishara S.W. and McReynolds R.L. (1996) Laboratory Ageing and Annealing of Asphalt Binders by Microwave Radiation. Transport Research Board, 1535, p.p. 98-107.

Bishara S.W; Robertson R.E; McReynolds R.L. and Mahoney D. (1999) Rapid and Simple Method for Binder Oxidative Ageing. Kansas Department of Transportation.

Bishara S.W; Robertson R.E; Shenoy A. and Mahoney D. (2003). Rapid Microwave Ageing of Modified Asphalts. 82 ${ }^{\text {nd }}$ Annual Meeting of the Transport Research Board.

BS EN 12697-26, 2004. Bituminous mixtures - Test methods for hot mix asphalt - Part 26: Stiffness. British Standards.

Clark D.(1996) Microwave Processing of Materials. Annual Review Material Science, Issue 26, p.p. 299-331.

Osepchuk J.M. (1984) A History of the Microwave Heating Applications. IEEE Transactions of Microwave Theory and Techniques, MTT-32, No. 9, Sept.

Shoenberger J; Rollings R. and Graham R. (1995) Properties of Microwave Recycled Asphalt Cement Binders. American Society for Testing and Materials. 1995/8 pp 199-213. 